\title{
O GRUPO PESQUISADOR CONSTRUINDO AÇÕES DE AUTOCUIDADO PARA O ENVELHECIMENTO SAUDÁVEL: PESQUISA SOCIOPOÉTICA
}

The research group building self-care actions for the healthy aging process: sociopoetic research El grupo investigador construyendo acciones de cuidar de si para el envej ecimiento
saludable: abordaje sociopoética

Iraci dos Santos

Aila Cristina dos Santos Alves ${ }^{2}$

Célia Pereira Caldas ${ }^{4}$
Alysson Fabio Leandro da Silva ${ }^{3}$

Rosimere Ferreira Santana ${ }^{6}$

\section{RESUMO}

Este trabalho teve como objetivo analisar os sentimentos de pessoas idosas sobre o autocuidado, à luz da Teoria de Nola Pender, que combina experiências cognitivas, crenças, hábitos e práticas, caracterizando a cultura e o modo de vida do grupo. Método sociopoético, mediante prática artística realizada em 2008 com participantes da UnAti-UERJ. Produção de dados submetida à análise temática sociopoética. Resultados: foram encontradas as categorias "Rosto coletivo do envelhecimento - as pessoas do grupo não se consideram idosas, conforme a discriminação cultural e social as visualizam"; e "A integralidade do autocuidado desmistificou-se a imagem da enfermeira atribuída somente ao cuidado físico, construindo-se o 'confeto': 0 autocuidado/ envelhecer é a busca de outra dimensão do viver. Conclui-se que ser idoso é adotar decisões positivas para reagir às adversidades que o envelhecimento possa provocar, utilizando seu potencial humano. Uma contribuição é valorizar o autocuidado como estratégia para o crescimento pessoal e o início de mudanças significativas.

Palavras-chave: Enfermagem. Gerontologia. Promoção da saúde. Autocuidado. Envelhecimento

\begin{abstract}
The aim of this study was to analyze the feelings of aged people regarding the self-care, accordingly to Nola Pender's Theory. This theory takes in consideration cognitive experiences, beliefs, habits and practices, in order to characterize the group's culture and lifestyle. The subjects were a group of participants from the Third Age Open University Program of Rio de Janeiro State University. The Data was collected through Art techniques and the data production was submitted to Sociopoetics thematic analysis. As results emerged the following categories: Collective face of the aging process - the group members do not see themselves as old, as represented by the cultural and social discrimination; The comprehensiveness of self-care - the image of the nurse attributed only to physical care was deconstructed, thus building the "conffect" (concept/affection) self-care/aging is the quest for another living dimension. To conclude, being old involves adopting positive solutions to face the difficulties regarding the aging process, using people's own human potential. A contribution may be to promote the self-care as a strategy for personal growth and as a start point for substantial changes.
\end{abstract}

Keywords: Nursing. Gerontology. Health Promotion. Self care. Aging

\section{Resumen}

Este trabajo tiene como objetivo analizar los sentimientos de ancianos sobre el autocuidado, en óptica de Nola Pender, que conjuga experiencias cognitivas, creencias, hábitos y prácticas, caracterizando la cultura y la manera de vivir del grupo. Método sociopoético, mediante práctica artística, realizada en 2008, con clientes de la UnAti-UERJ. Se utilizó el análisis temática sociopoética. Resultados: categorías - Rostro colectivo del envejecimiento - las personas del grupo no se sienten viejas, al revés de la discriminación cultural y social; La integralidad del cuidar de si - hube desmitificación de la imagen de la enfermera atribuida solamente al cuidado físico, construyéndose el concepto: el cuidar de si/envejecer es la búsqueda de otra dimensión del vivir. Se concluyó, que ser viejo es adoptar decisiones positivas para reaccionar las adversidades que el envejecimiento pueda provocar, utilizando su potencial humano. Una contribución es valorar el autocuidado como estrategia para el crecimiento personal y el inicio de cambios significativos.

Palabras clave: Enfermería. Gerontología. Promoción de la Salud. Autocuidado . Envejecimiento

\footnotetext{
${ }^{1}$ Doutora em Enfermagem. Professora do Departamento Fundamentos de Enfermagem e do Programa de Pós-Graduação da Faculdade de Enfermagem da Universidade do Estado do Rio de Janeiro. Bolsista de Produtividade em Pesquisa do CNPq. Líder do Grupo de Pesquisa CNPq-Concepções teóricas para o cuidar em saúde e enfermagem. Rio de Janeiro - RJ. Brasil. E mail: iraci.s@terra.com.br ;2 Enfermeira. Mestre pelo Programa de Pós-Graduação da Faculdade de Enfermagem da Universidade do Estado do Rio de Janeiro. Rio de Janeiro - RJ. Brasil. E-mail: ayla_alves@ibest.com.br; ${ }^{3}$ Enfermeiro do Hospital Servidores do Estado. Mestrando do Programa de Pós-Graduação da Faculdade de Enfermagem da Universidade do Estado do Rio de Janeiro. Rio de Janeiro - RJ. Brasil. Email: alyssonrio@yahoo.com.br; ${ }^{4}$ Doutora em Enfermagem. Professora do Departamento de Saúde Pública e do Programa de Pós-Graduação da Faculdade de Enfermagem da Universidade do Estado do Rio de Janeiro. Vice- Diretora da UnATI/UERJ. Rio de Janeiro - RJ. Brasil. E mail: celpcaldas@gmail.com ; 5 Doutora em Enfermagem. Professora do Departamento de Enfermagem Médico Cirúrgica e Coordenadora do Núcleo de Extensão e Cultura da Faculdade de Enfermagem da Universidade do Estado do Rio de Janeiro. Rio de Janeiro - RJ. Brasil. E mail: I.m.b@uol.com.br ; ${ }^{6}$ Doutora em Enfermagem. Professora Adjunta do Programa de Pós-Graduação da Escola de Enfermagem Aurora Afonso Costa da Universidade Federal Fluminense. Rio de Janeiro - RJ. Brasil. E-mail: rosifesa@yahoo.com.br
} 


\section{INTRODUÇÃO}

0 envelhecer faz parte do viver e da história da humanidade, sendo que esta realidade transformou-se de um fato isolado para o fato globalizado. A "geriatrização" da sociedade, que significa aumento da proporção de idosos na população, ${ }^{1}$ emergiu no final do século XX, significando um fenômeno social importante, principalmente após o avanço de tecnologias científicas, aliado à possibilidade de usufruir a longevidade, considerando a qualidade de vida alcançada. Esse fenômeno já era visualizado nos países desenvolvidos, mas desde o início da última década tornouse impossível sustentar tal visão. 0 Censo de 1980 contabilizava 8 milhões de pessoas idosas, subindo em 1991 para 10,6 milhões. Em 2000, o Censo confirmou o fenômeno citado, registrando 14,5 milhões de pessoas idosas, sendo que os países em desenvolvimento, como o Brasil, apresentam uma população de idosos correspondente a $10,5 \%$ da população total. ${ }^{2}$

Desde 1982, define-se a população idosa a partir dos 60 anos de idade, parâmetro válido para os países em desenvolvimento; subindo para 65 anos de idade quando se trata de países desenvolvidos. ${ }^{3}$ Assim, com a "geriatrização" da sociedade, firmada através dos avanços de tecnologia em saúde e redução das taxas de fertilidade, observa-se, na atualidade, a grande variação da atitude e comportamento das pessoas quando atingem a idade citada. Desse modo, este trabalho considera o alerta quanto à necessidade de ampliação de estudos do envelhecimento, vendo-o como multifacetado, tendo a enfermagem um papel fundamental de promotora da saúde e de um envelhecimento saudável. ${ }^{4}$.

É necessário ampliar estas visões para que o enfermeiro perceba a amplitude do atraente universo dos indivíduos idosos com os quais muito se tem a aprender. Em retribuição, oferecerIhes um cuidado de saúde cuja perspectiva é o sujeito em sua singularidade, pois eles são únicos, capazes de se adaptar, de crescer e de aprender. São adultos maduros em contínua mudança, marcados por muitos preconceitos em uma sociedade ainda despreparada para encarar os desafios dessa nova realidade.

A questão é fazer com que o prolongamento da vida seja acompanhado do viver com qualidade, principalmente quando se refere aos países em desenvolvimento, onde existem poucas soluções satisfatórias. As necessidades da infância se defrontam com a emergência de ter diante de si outra população também com problemas sociais econômicos graves, buscando atendimento de suas demandas específicas. ${ }^{5}$ Refletindo sobre o papel da enfermeira como educadora junto àqueles que enfrentam o envelhecimento, apresenta-se o problema de pesquisa: Como incentivar pessoas idosas a lutarem por sua qualidade de vida através da orientação para o autocuidado? Neste recorte de dissertação de mestrado, tem-se como objetivo analisar os sentimentos de pessoas que vivenciam a fase do envelhecimento, utilizando prática de dinâmica de grupo incentivadora do imaginário.

Esta proposta de investigação justifica-se porque 0 envelhecimento liga-se à ideia de mudança contínua, tratandose de um sistema instável no qual a cada instante é necessário reconquistar o equilíbrio perdido. Daí, as pessoas idosas, em alguns momentos de suas vidas, negligenciam e deixam de se cuidar, perdendo a autoestima que é indispensável, principalmente nessa fase da existência, em consequência das perdas e danos sofridos.

\section{REFERENCIAL TEÓRICO}

Os motivos básicos para o envelhecimento da população referem-se à redução dos índices de mortalidade e diminuição da taxa de natalidade; outro se deve ao aumento da longevidade de pessoas com 60 anos e mais, considerando o número médio de anos de vida registrado em 2006. Estima-se que, quando uma pessoa completa 60 anos, ela viva mais 19,41 anos, se do sexo masculino e 22,56 anos, se do sexo feminino. ${ }^{6}$ Há, também, outro fator, a migração, que ajuda a alterar a distribuição etária de uma população. Esses fatos asseguram o contínuo "agrisalhamento" da população mundial. ${ }^{7-8}$

Nessa assertiva, a longevidade do homem revela 0 atendimento de um desejo de todos os tempos. Porém, isso é insuficiente; é fundamental que o aumento da expectativa de vida acompanhe a qualidade de vida, sem a qual envelhecer torna-se um fardo pesado para a sociedade, para a família e, principalmente, para a pessoa idosa. Atualmente, a cena pública traz as múltiplas dimensões do envelhecer e as possíveis intervenções em saúde. Considerando essas dimensões, a heterogeneidade se faz presente nos diferentes aspectos, pois temos diferentes idades biológicas e subjetivas em indivíduos com a mesma idade cronológica. ${ }^{9}$ E isto se deve às dificuldades encontradas para operacionalizar, nas práticas de saúde, estratégias que busquem a interferência no estilo de vida no contexto das condições econômicas, sociais e ambientais determinantes da saúde.

Propiciar ao indivíduo opções mais saudáveis talvez seja uma tarefa fácil. Entretanto, incentivar a adoção de comportamentos mais positivos na fase do envelhecer, pode ser uma tarefa árdua. Além disso, o fato de ele adotar uma mudança de atitude pode demorar muito para causar mudança de comportamento, que pode não ocorrer, em alguns casos. Recorda-se que, geralmente, os conhecimentos são seguidos de recomendações de mudanças de hábitos e oferecidos como antídotos às vulnerabilidades apresentadas.

Esse propósito de construção de um novo modo de envelhecer revela que as pessoas que envelhecem procuram se cuidar, por pretender viver mais tempo, mesmo tendo a morte como horizonte inexorável. Pensando assim, o objetivo da enfermagem é ajudá-las nesse intento, cujo alcance depende de uma abordagem que valoriza o autocuidado, tendo como 
princípio a estimulação para melhoria de sua condição de vida e preservação da saúde. ${ }^{10}$ Essa abordagem de promoção da saúde é um modelo fundamental para estudar o modo como os indivíduos idosos tomam as decisões sobre o cuidado de sua própria saúde dentro do contexto da enfermagem, ${ }^{10}$ pois diversos estudos demonstram o adoecimento crônico dessa população, inclusive a prevalência da hipertensão arterial. ${ }^{11}$

0 autocuidado é uma forma de comportamento individual relacionado à saúde. Assim, as atividades de promoção ligam-se à combinação de experiências cognitivas, crenças, hábitos e práticas que caracterizam o modo de vida do grupo e a cultura à qual o indivíduo pertence, enquanto o desempenho de tais atividades envolve necessariamente uma decisão, uma escolha. ${ }^{10} \mathrm{~A}$ decisão e a escolha devem ser incorporadas de modo ativo, ao invés de passivo, tornando-se a pessoa também responsável pela sua saúde, e não apenas as políticas públicas de saúde. Contudo, não apenas os fatores internos ao indivíduo, mas também o contexto em que ele vive, interfere no seu conhecimento ou habilidade de refletir, julgar e decidir, influenciando na sua capacidade de adotar uma postura favorável ao autocuidado. ${ }^{10}$

0 autocuidado contribui para que a pessoa idosa melhore o seu convívio familiar e social, ampliando sua autonomia e autoestima com vistas ao envelhecer saudável. Ele cria condições favoráveis que facilitam e incentivam a diminuição da dependência na relação profissional-clientefamília e a prevenção de sequelas negativas.

\section{METODOLOGIA}

Para pesquisar o imaginário de um grupo de pessoas idosas participantes da Universidade Aberta para Terceira Idade (UnAti), vinculada à Universidade do Estado do Rio de Janeiro (UERJ), a fim de conhecer os valores e os princípios norteadores de seu pensamento sobre a construção das ações de autocuidado para o envelhecimento saudável, escolheu-se um método que possibilita ouvir e vê-las expressarem as várias maneiras de se "encontrar e desencontrar" no cuidar de si, em um espaço gerador de liberdade propício à criatividade. ${ }^{12}$

Nesse espaço se desvela a sociopoética, considerando que este método favorece o conhecimento de forma reflexiva e natural, aumentando o grau de consciência dos sujeitos sobre o tema de investigação, estimulando-os a fazerem outras associações e, até mesmo, construindo outro imaginário sobre o objeto de estudo proposto. Desse modo, situa-se também o pesquisador ativamente engajado no processo de pesquisa, todavia sem interferir na livre expressão do imaginário dessas pessoas, na posição de quem aprende com elas. $^{12}$

Aplicando seus princípios filosóficos: 1) considerar os sujeitos de pesquisa como corresponsáveis pelos conhecimentos produzidos, junto ao pesquisador. Assim, acontece a potencialização dos sujeitos que compõem o grupo, e todos os integrantes se constituem como copesquisadores, caracterizando a instituição do dispositivo analítico da sociopoética, denominado Grupo Pesquisador (GP);

2) Destacar a importância do corpo fonte de conhecimentos. A utilização do corpo como fonte de saberes desvela o potencial humano para expressar: sensação, emoção, gestualidade, imaginário, intuição, pensamento e razão;

3) Valorizar o papel da criatividade do tipo artístico. Nesse sentido, as técnicas de produção artística desenvolvidas pelo grupo promovem a criatividade no aprender, no conhecer, no pesquisar e no cuidar do ser humano. Elas "incentivam o imaginário caracterizando a sociopoética como um método revelador e catalisador da heterogeneidade, que muitas vezes oculta uma aparente homogeneidade" 12:60;

4) Destacar a importância das culturas dominadas e de resistência, das categorias e dos conceitos que elas produzem. Tal fato valoriza os "confetos", produzidos pelo GP. Explicita-se que confeto é um neologismo criado por Jacques Gauthier, criador da sociopoética, significando conceito+afeto, ou seja, a união de pensamento e sentimentos ${ }^{12}$;

5) Considerar a importância do sentido espiritual, humano e político da construção dos saberes. Assim, a sociopoética é um método de construção coletiva do conhecimento, pois todos os saberes são iguais em direito ${ }^{12-13}$, considerando que:

Há uma relação dinâmica entre o mundo real e o sujeito, uma interdependência viva entre o sujeito e o objeto, um vínculo indissociável entre o mundo objetivo e a subjetividade do sujeito. 0 conhecimento não se reduz a um rol de dados isolados, conectados por uma teoria explicativa. O objeto não é um dado inerte e neutro; está possuído de significados e relações que sujeitos concretos criam em suas ações. Como sujeitos da pesquisa, identificam os seus problemas, analisam-nos, discriminam as necessidades prioritárias e propõem as ações mais eficazes $^{12: 79-83}$.

$\mathrm{Na}$ sua fundamentação teórica, encontram-se a Pedagogia do Oprimido de Paulo Freire, a escuta mitopoética de René Barbier, o Teatro do Oprimido de Augusto Boal, a Análise Institucional de René Lourau e a Esquizoanálise de Giles Deleuze e Felix Guattari. Ao desenvolver uma postura dialógica, busca uma igualdade entre todas as informações dos membros do grupo e facilitadores da pesquisa. ${ }^{12}$

A sociopoética orienta-se pelos princípios, já explicitados, que são aplicados simultaneamente com seus fundamentos teóricos para desenvolver as seis etapas da pesquisa: investigação temática; produção e análise de dados junto ao GP; contra-análise dos dados, organizados pelo pesquisador, pelo GP; apresentação dos resultados dos dados produzidos; validação dos resultados pelo GP; e avaliação da pesquisa. Todos os princípios filosóficos têm a mesma 
importância, porém só se considera método sociopoético quando há Instituição do Grupo Pesquisador. ${ }^{12}$

Ressalta-se que o imaginário na pesquisa sociopoética é refletido pelo "inconsciente, que carrega as aceitações e cumplicidades com os poderes hegemônicos, as repressões instituídas, as ideologias dominantes" 12:53. Utilizando este criar, revela-se e analisa-se coletivamente; logo, parcialmente superam-se essas aceitações e cumplicidades. 0 desenvolvimento do GP reflete a função educadora que envolve o cuidar em enfermagem, permitindo uma educação compartilhada, mais próxima da realidade das pessoas. Quando a enfermeira educa para 0 autocuidado, desenvolve um papel diretamente político, ao facilitar a autonomia de grupos sociais geralmente alvos de políticas públicas assistencialistas, que as mantêm na dependência das falhas do sistema de saúde. ${ }^{13-14}$

\section{A Instituição do Grupo Pesquisador}

Para instituir o GP obteve-se aprovação do Comitê de Ética em Pesquisa, Protocolo n. 025.3.2008 dos responsáveis pela UnATI/UERJ, campo da pesquisa, sendo enfatizado o compromisso ético com os sujeitos da pesquisa. Lembrando os referenciais básicos da bioética, autonomia, não maleficência, beneficência e justiça, os sujeitos aceitaram participar do estudo após ler, concordar e assinar o Termo de Consentimento Livre e Esclarecido. Após esses trâmites legais de responsabilidade, foi instituído o Grupo Pesquisador, aqui denominado copesquisador. A pesquisadora assumiu o papel de facilitadora, sendo responsável por desenvolver dinâmicas de relaxamento, técnicas artísticas de produção de dados, junto a mais quatro colaboradores, incluindo a orientadora da dissertação, colegas de turma de mestrado e um especialista em dinâmicas de sensibilidade.

Nesta pesquisa, visando incentivar a adesão de frequentadores do campo selecionado, para compor um grupo de investigação, desenvolvido através de Oficinas de Trabalho/estudo, denominadas sociopoéticas, foi proposto aos participantes da UnATI/UERJ um Curso para o Autocuidado, que funcionou como um atrativo aos sujeitos de pesquisa. Foi concedida pela UnATI uma sala para realização do curso e da pesquisa nas dependências desta instituição. A divulgação do Curso deu-se mediante cartazes anexados ao mural da UnATI/UERJ, na sua Recepção e, também pelos profissionais de saúde.

Para a seleção dos sujeitos foram considerados os critérios de inclusão: ter idade superior ou igual a 60 anos; $\mathrm{e}$ aceitar participar do Curso/Pesquisa Autocuidado no Envelhecer Saudável. Os sujeitos pertenciam a qualquer classe social, sexo, raça ou etnia. Abertas 20 vagas, somente 11 pessoas puderam participar do curso/pesquisa que ofertou nove encontros semanais de 1 hora e meia de duração, desde o desenvolvimento das fases do GP, ocorrido de outubro a novembro de 2008. A gravação das falas foi realizada nas oficinas de produção de dados mediante a anuência dos nove sujeitos, que efetivamente participaram da pesquisa.

Por ser o dispositivo analítico Grupo Pesquisador o centro vivo da pesquisa sociopoética ${ }^{12}$, optou-se por descrever , neste trabalho, a etapa da investigação temática como um espaço de pesquisar/cuidar/educar em relação às experiências vivenciadas sobre ações de autocuidado. Ressalta-se, aqui, na fase de delimitação do tema orientador de pesquisa (Como você se cuida para o envelhecimento saudável?), que a produção de dados foi conduzida pela apropriação da Teoria da Ação Dialógica, de Paulo Freire, principalmente aplicando-se o princípio da co-laboração. ${ }^{14-15}$

Assim, referente aos objetivos dessa pesquisa, as pessoas idosas se uniram em co-laboração para desvelarem o mundo das ações de autocuidado para o envelhecimento saudável, princípio este também atendido em vários momentos do GP quando se discutiram/analisaram os dados por elas produzidos. Então, no espaço do grupo, os saberes foram compartilhados ${ }^{15-17}$, rompendo-se com a visão distorcida do saber unilateral, inquestionável e até mesmo imposta pelos profissionais de saúde, que se consideram os únicos detentores do saber nessa área. ${ }^{17}$

Este princípio destaca a participação efetiva do sujeito da pesquisa, promovendo a construção coletiva do saber. Portanto, a investigação temática com os membros do grupo pesquisador só se justifica enquanto se devolve a ele o que a ele pertence, e na medida em que seja não somente 0 ato de conhecê-lo, mas o de conhecer com ele a realidade que o desafia. Então, a dialogicidade começa na investigação temática. ${ }^{14-15}$ No primeiro encontro, percebendo-se a dificuldade de alguns participantes em se apresentar e falar em grupo, foi proposta uma dinâmica, ${ }^{16}$ como forma de descobrir/conhecer, liberar e potencializar a criatividade e entrosamento dos sujeitos e com os facilitadores da investigação.

\section{Dinâmica de Sensibilidade - A Construção do Rosto Coletivo}

Essa dinâmica promoveu a desinibição dos participantes, socializou o espaço/tempo do desenvolvimento da oficina, havendo maior concentração para iniciar a investigação. Passos da dinâmica ${ }^{16}$ : posicionamento em círculo; distribuição de material para desenho aos participantes (folha de papel e canetas de cor); orientação para cada participante desenhar um elemento do rosto (boca, nariz, queixo, orelhas, sobrancelhas, cabelos) de cada vez e passar o desenho da folha de papel para as pessoas da direita e pegar a folha das pessoas da esquerda. Ao finalizar o rosto coletivo, contemplar o desenho e identificar as características físicas, traços, fisionomia, expressões do rosto, de sua personalidade. Pedir a cada participante para dizer que sentimentos vieram em sua mente e as características físicas 
que mais se aproximam de sua autoimagem.

A produção de dados utilizando a dinâmica descrita foi desenvolvida após o relaxamento corporal através de exercícios respiratórios e alongamento corporal em oficinas com duração de três horas. Essa produção foi submetida à análise, visando descobrir, mediante leitura intuitiva, o que os desenhos/figuras (o rosto coletivo) comunicavam. Tal leitura foi complementada pela descrição de cada participante sobre sua mentalização do desenho por ele elaborado. As respostas escritas de cada membro do GP, sobre o rosto coletivo e sobre o autocuidado, foram consideradas como temas correspondentes à estrutura do pensamento individual. Tais temas foram reunidos formando os temas grupais, que revelaram a estrutura do pensamento grupal, ou seja, do grupo pesquisador. A delimitação dos temas grupais originou duas categorias: 0
Rosto Coletivo do Envelhecimento Saudável e A integralidade no Autocuidado (Figura 1 e Figura 2).

\section{RESULTADOS E DISCUSSÃO}

Os resultados são descritos iniciando-se com as falas do grupo pesquisador, ao interpretarem suas produções artísticas (Figuras 1 e 2), simbolizando as categorias temáticas. Alerta-se, que, em sociopoética, a produção é do grupo. Portanto, a descrição dos resultados refere-se ao sentido/significado dos temas grupais. Inexiste descrição destacando estrutura de pensamento individual, pois as respostas de todos os membros do grupo são validadas dentro do GP.

\section{Rosto Coletivo do Envelhecimento Saudável}

Figura 1- 0 Rosto Coletivo do Envelhecimento Saudável.

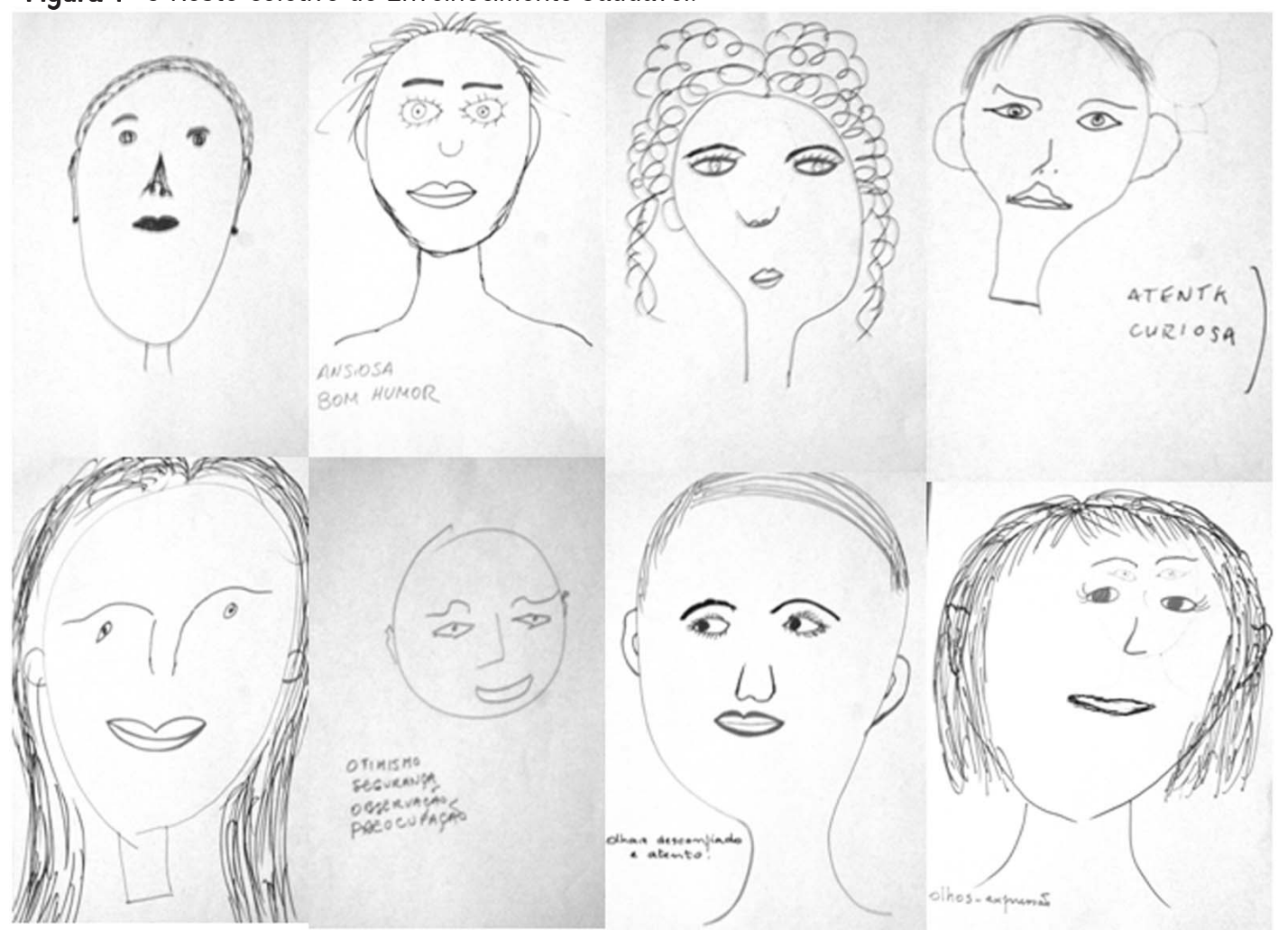

Fonte: Alves ACS. Sociopetizando a construção das ações de autocuidado no envelhecimento saudável: Uma aplicação da Teoria de Nola Pender [dissertação]. 2009; Rio de Janeiro: Faculdade de Enfermagem-UERJ.

"Aqui a boca teria a ver comigo, a sobrancelha, porque está assim franzida. Tenho bastante otimismo, sou uma pessoa segura, decidido e bastante observador". "Sobre a minha foto aqui, a única coisa que deu de expressão foi os olhos, que é o meu caso. Eu acho que a expressão dos meus olhos, o meu rosto, a minha fisionomia está sempre com um olhar alegre, de felicidade, apesar de que todos nós temos problemas, mas ela está com um sorriso, éo meu caso, eu estou sempre assim". "Este rosto me parece uma pessoa ansiosa que tem haver comigo e meu bom humor". "O que mais me chamou atenção aqui são as sobrancelhas e os olhos, porque a sobrancelha está muito bonita e um olhar atento. Parece alguém que está atento ao que está acontecendo, combina comigo a maior parte do tempo" (Grupo Pesquisador).

"Essa figura... os olhos me deram assim uma ideia desconfiada e atenta, esse cabelinho aqui, que desenharam, parecido de homem, é o meu achatadinho [risos], a boca também saiu parecida com a minha. Então está de bom tamanho". "Eu achei o rosto coletivo uma pessoa muito parecida 
com a minha curiosidade que é uma coisa inata e muito atenta". "Eu não tenho nada a declarar... Eu sou muito tímida! Eu não encontrei nada que parece comigo". "Aúnica coisa que eu encontrei aqui foio cabelo, que é um pouco rebelde, meio rebelde. Tem tanta coisa para falar... Sou alegre, mas depende do momento" (Grupo Pesquisador).

Vê-se na Figura 1 que a dinâmica de sensibilidade e produção artística proporcionou ao grupo intensa participação, que foi importante para prosseguir com a pesquisa. ${ }^{12-13}$ Releva-se nessa produção que os membros do GP não desenharam no rosto coletivo traços de envelhecimento, compatíveis com sua idade cronológica, com as perdas e danos sofridos na continuidade da vida, com o sofrimento consequente de enfermidades comuns nesta fase do viver. ${ }^{4}$ Assim, o GP, igual a outros indivíduos idosos, prefere destacar sua boa saúde, talvez se reportando a outras dimensões corporais. ${ }^{3-6,18}$ Desse modo, percebe-se que essas pessoas simplesmente se consideram pessoas não idosas, conforme a discriminação cultural e social as visualizam.

Assim, apesar do receio de revelar ao grupo o tema orientador referente aos sentimentos do envelhecer, visando a investigação temática, apresentou-se a questão: "0 que vocês pensam quando ouvem a palavra autocuidado?”.

\section{A integralidade no autocuidado}

Figura 2 - Cartaz sobre 'Autocuidado' desenvolvido com o GP. Rio de Janeiro, UERJ, 2008.

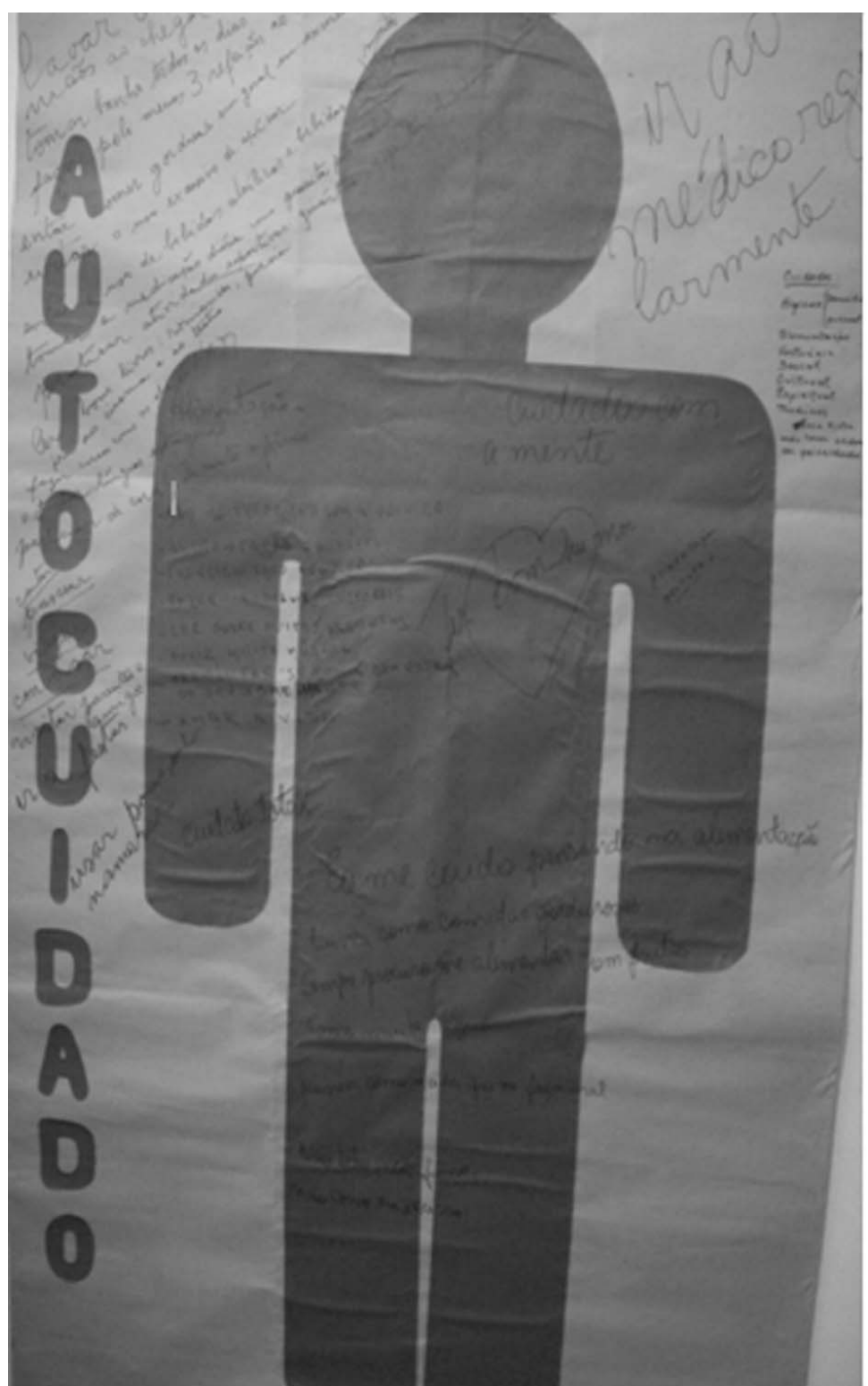

- lavar as mãos ao chegar a casa;

- tomar banho todos os dias, fazer pelo menos três refeições ao dia;

- evitar comer gorduras em geral em excesso; usar pouco sal; - evitar o uso excessivo de açúcar;

- evitar o uso de bebidas alcoólicas e bebidas com muita cafeína;

- tomar a medicação diária como prescrita pelo médico; - praticar atividades esportivas: ginástica, yoga, tai-chi, dança de salão, hidroginástica;

- ler bons livros: romances, poesia;

- ir ao cinema e ao teatro;

- fazer cursos como os da UnATI;

- estudar línguas estrangeiras;

- participar de coral de canto orfeônico;

- cantar, passear, viajar, conversar, namorar, ir a festas;

- visitar parentes e amigos;

- cuidado total;

- alimentação saudável;

- não se preocupar com a velhice;

- exercício físico regular;

- fazer programas culturais;

- ler sobre muitos assuntos;

- ouvir muita música;

- preocupar-se com o bem-estar e do seu semelhante;

- amar a vida;

- ter bom humor;

- ir ao dentista;

- cuidados com a mente;

- ir ao médico regularmente;

- higiene doméstica e pessoal;

- vestuário;

- social, cultural, espiritual;

- tomar muita água;

- nunca comer comidas gordurosas, sempre procurar se alimentar com frutas;

- nunca comer nada que faça mal;

Fonte: Alves ACS. Sociopetizando a construção das ações de autocuidado no envelhecimento saudável: Uma aplicação da Teoria de Nola Pender [dissertação] . 2009; Rio de Janeiro: Faculdade de Enfermagem-UER. 
Autocuidado por você próprio"; "Cuidado em todos os aspectos: espiritual, emocional, mental, físico (...)"; "Pensei só em saúde”; "Em remédios de como se cuidar"; "Orientar para o nosso bem-estar"; "Autocuidado tanto físico, quanto espiritual, o modo de ser, de vestir, de calçar, de expressar, (...)"; "0 autocuidado pra mim, ele denota muito mais o aspecto físico do que o aspecto espiritual, porque primeira é a preocupação da própria atividade, do trabalho, que é como a pessoa da terceira idade a partir de certo momento começa a ter o seu organismo fragilizado pelo físico, problema de se locomover, descer uma escada, subir uma escada, tomar um banho(Grupo Pesquisador)

Pessoas que não conseguem entrar no banheiro se não houver um tapete antiderrapante e não admitem que já teve problema de escorregar com sabão. Aí....,esse corpo já começa a perceber que já não tem o mesmo equilibrio. Então, esse cuidado me chamou a atenção, olhando esse aspecto, da maneira de se proteger com relação a essa fragilização física”; "Em minha opinião a gente não deve se preocupar só com o físico, deve se preocupar também com o espiritual"; "Aqui cabem todos os meios; (Grupo Pesquisador)

\section{Mas pra mim o autocuidado dentro do foco do curso me chamou a atenção pelo fato de ela ser enfermeira, tratar o físico e não o espiritual". "Mas especificamente do curso, eu acho que é um tratamento do físico, comportamento, alimentação, qualquer coisa assim referente ao corpo da pessoa, já que ela é enfermeira. (Grupo Pesquisador)}

Sobre as considerações feitas pelo grupo, a princípio foi desmistificada a imagem da enfermeira atribuída somente ao cuidado físico, ${ }^{13,17}$ pois, além desse, o princípio ético na enfermagem revela uma estética advinda da subjetividade interior objetivada nas práticas de cuidar de pessoas respeitando seus direitos e reconhecendo sua dignidade humana. Fazer enfermagem é dispor-se a sonhar, imaginar, criar e compartilhar com outros as belezas, misérias, forças, humildade, saberes e utopias. ${ }^{17}$

Após o término da oficina sociopoética, o GP também considerou válido e importante sobre experiências pessoais de autocuidado, por se tratar de uma ação vivida e refletida pelas pessoas idosas. Assim foi construído o "confeto": 0 autocuidado /envelhecer é a busca de outra dimensão do viver. Tal dimensão pode ser encontrada não apenas através da ciência consagrada, das tecnologias, mas pela responsabilidade do cuidar de si, adotando hábitos saudáveis adquiridos no percurso da vida.
Ressalte-se que o GP apresentou uma intensa curiosidade sobre o que viria ser a palavra sociopoética, e, quando esclarecido pelas facilitadoras da pesquisa, percebeu como seria vasto e produtivo sua participação, pois relatou:

Ao falar alguma coisa, ao dar um depoimento, de alguma maneira dar certa contribuição. Fazer você a construção, refletir, para nós é gratificante, $e$ saber que valeu para alguma coisa, a gente ser ouvido, é sempre importante, ser ouvido, ser levado em consideração (Grupo Pesquisador).

Ao iniciar o Curso de Autocuidado, esclareceu-se que autocuidado é uma prática de cuidar de si desenvolvida pela própria pessoa. São atitudes e comportamentos que a pessoa tem em seu próprio benefício, com a finalidade de promover sua saúde, de preservá-la, de assegurar e manter a vida. Um recurso para sobrevivência, porque, ao cuidar do corpo, não apenas a estrutura física, mas também das dimensões mental e espiritual, o indivíduo compreende melhor e de maneira mais construtiva a sua própria vida.

Todavia, ter a consciência das próprias necessidades de saúde e de se fazer o que é preciso para se cuidar gera o entorno que chamamos de autoconhecimento. Será que nós nos conhecemos o suficiente para sabermos o que nos estimula ou nos desestimula sobre os cuidados de saúde? Pois para cuidar de si devemos saber o que é melhor para si, ou pelo menos tentar minimizar aquilo que nos é prejudicial. Então, acredita-se que o autocuidado precisa ser vivido, ser sentido, ser construído a cada dia. Já que esta é uma construção dinâmica e a todo o momento cria e recria novos conhecimentos, o cuidar é visto como forma de criar, uma possibilidade de intervir e também de transformar as situações. E para transformar uma situação de cuidado se faz necessário modelar movimentos e ações que fazem o cuidado se tornar existente nas nossas vidas. "Acreditamos que, se vocês participam de um curso na UnATI/UERJ, é porque algo fizeram para que se tornasse existente o cuidado em suas vidas". Então, os membros do GP responderam a outra pergunta orientadora da pesquisa: "Como vocês se cuidam para o caminho do bom envelhecer?", elaborando um Cartaz sobre Autocuidado (ver Figura 2).

Constatou-se que propiciar liberdade de escolhas ao grupo para desenvolver a pesquisa junto à pesquisadora caracteriza a adesão autêntica de ação dialógica. ${ }^{12-15,17}$ Essa adesão ao tema e às dinâmicas fez com que os sujeitos se voltassem sobre a realidade mediatizadora do autocuidado que, problematizada, éjá a ação dos sujeitos dialógicos sobre ela, e daí uma transformação desta. A intenção em aceitar e acreditar nesta tarefa e na possibilidade de refletir sobre as experiências vivenciadas com o GP e os facilitadores permitiu o pesquisar/cuidar/educar em enfermagem de modo sensível, humanizado e estético, ${ }^{12,15,17}$ entendendo-se que ensinar é 
pesquisar e pesquisar sociopoeticamente é ensinar, e, ainda, concordando-se que pesquisar sociopoeticamente em enfermagem é cuidar. ${ }^{17}$

Verificou-se, ainda, na investigação temática, que, com esses resultados, a sociopoética cria dispositivos geradores de espaços e tempos para que as pessoas, individualmente segundo uma vertente e grupalmente segundo a outra, tomem poderes os mais amplos possíveis na produção de conhecimento, e na realização da pesquisa, até o fim, a socialização. ${ }^{12}$ Finalizando as oficinas, consideradas muito produtivas sobre 0 assunto da pesquisa, o GP elaborou um cartaz com uma frase, uma palavra, constituindo um desenho sobre suas práticas relacionadas ao autocuidado conforme se observa na Figura 2.

Analisando o conteúdo dessas falas, observase a preocupação do GP com práticas de saúde física, mental/ emocional/intelectual/cultural e espiritual, reveladoras de seu autocuidado na integralidade. Além de sua compreensão sobre o atendimento de suas necessidades humanas, o grupo mostrase integrado e atualizado com os avanços do conhecimento em saúde, inclusive quanto às práticas de terapias complementares, lazer e opções intelectuais e pertencimento a grupos e associações de interesses comunitários. Ressalta-se, ainda, sua preocupação e compromisso com membros de sua constelação familiar e amigos ${ }^{18}$ ao sentir-se responsável por eles conforme revela o que descreveram como ações de autocuidado: "visitar parentes e amigos; preocupar-se com o bem-estar e do seu semelhante"(ver Figura 2).

\section{CONCLUSÃO}

A produção do conhecimento do grupo pesquisador sobre 0 autocuidado, a partir da investigação temática para desenvolver um estudo sobre autocuidado entre pessoas idosas, revelou, de maneira clara e simples, a preocupação de cada sujeito em cuidar de sua saúde. Alguns demonstram que têm consciência da necessidade de frequentar sistematicamente o médico e de seguirem suas orientações. Eles consideram importante tomar os medicamentos corretamente, manter a higiene corporal e alimentação adequada e realizar atividade física. Atribuem considerável valor à convivência com os amigos e à participação nos grupos de "melhor idade" como ações promotoras de saúde/bem-estar.

Portanto, essas pessoas ao assumirem determinados comportamentos e atitudes, estão determinando seu processo de viver que consideram aç̃̃es saudáveis, estas, por sua vez, embasadas no seu próprio conhecimento em saúde adquiridos em suas experiência e vivências.

A construção do Rosto Coletivo mostrou a adesão do grupo à dinâmica de sensibilidade para incentivar o imaginário e a criatividade, revelando pessoas com sentimentos de autoimagem e autoestima preservadas, apesar de seu autoconhecimento quanto às limitações do seu envelhecimento. Suas falas a partir dessa produção demonstram sua alegria por compartilhar com outras pessoas de sua idade cronológica, momentos de interesse na continuidade da vida, mesmo considerando perdas e danos.

É imprescindível socializar esses saberes aliados aos saberes acadêmicos, para entender o imaginário sobre 0 autocuidado durante toda a vida, ou melhor, desde que nascemos, pois a partir desse momento já se começa a envelhecer. É uma prática que, de acordo com o GP, deve iniciarse desde a infância, incentivando o conhecimento do seu próprio corpo e como tudo funciona para se cuidar melhor, pois muitas pessoas chegam à velhice sem se conhecer.

Observou-se a validade da investigação junto ao Grupo Pesquisador, mesmo quando o facilitador sugere o tema, com bastante abertura, evitando induzir determinando aspectos. Assim, junto aos copesquisadores, descobrem-se os eixos de problematização, ou seja, analisa-se criticamente 0 que 0 assunto encerra. Então, a produção deste conhecimento em sociopoética foi construída a partir do desejo de saber do GP, e não exclusivamente dos interesses e da curiosidade do facilitador da pesquisa.

Através dos conhecimentos produzidos concluiu-se que ser pessoa idosa na atualidade é adotar decisões positivas para reagir às adversidades que o envelhecimento possa provocar, utilizando seu potencial humano para viver com qualidade, apesar dos possíveis adoecimentos e perdas financeiras, econômicas e afetivas.

Espera-se que esta pesquisa contribua fortalecendo a competência do profissional de enfermagem quanto às condições e possibilidades de aplicação dos resultados em benefício da saúde da pessoa idosa. Acredita-se que se deve avançar na busca pela explicitação de tais elementos ligados ao imaginário na construção das ações de autocuidado, como também a promoção da saúde centrada no ensino do autocuidado precisa fazer parte do ensino de Graduação em Enfermagem para que o aluno seja capaz de compreender esse novo olhar.

\section{REFERÊNCIAS}

1. Papaléo Netto M. 0 estudo da velhice: histórico, definição do campo e termos básicos. In: Freitas EV, et al. Tratado de Geriatria e Gerontologia. $2^{\mathrm{a}}$ ed. Rio de Janeiro: Guanabara Koogan; 2006. p. 10.

2. Instituto Brasileiro de Geografia e Estatística- IBGE. Censo 2000. [site da Internet] [citado 2008 fev 01]. Disponível em: www.ibge.gov.br/ censo.

3. Organização Panamericana de Saúde- OPAS. Envejecimiento y salud: un cambio de paradigma. Rev Panan Salud. 2000; 7(1): 60-7.

4. Berger LM, Mailloux-Poirier M. Pessoas idosas: uma abordagem global. Lisboa: Lusodidacta; 1995. 
5. Veras RP. Atenção preventiva ao idoso: uma abordagem de saúde coletiva. In: Papaléo Netto M, organizador. Gerontologia. São Paulo: Atheneu; 1996. p 383.

6. DATASUS. [site da Internet] [citado 2008 jan 23] Disponível em: http:/ /www.tabnet.datasus.gov.br/cgi/idb2006/matriz.htm.

7.Wong PTP, organizador. 0 envelhecimento da população brasileira e o aumento da longevidade: subsídios para políticas orientadas ao bemestar do idoso. Belo Horizonte: UFMG/Cedeplar/ABEP; 2001.

8. Pereira MG. Epidemiologia: teoria e prática. In: Transição demográfica e epidemiológica. Rio de Janeiro : Guanabara Koogan; 2000. p 157-85.

9. Paschoal SMP. Epidemiologia do envelhecimento. In: Papaléo Netto M. Gerontologia: a velhice e o envelhecimento em visão globalizada.São Paulo: Atheneu; 1996. p 26-43.

10. Sakraida, TJ. Nola Pender: health promotion model. In: Tomey AM, Alligood MR. Nursing theorists and their work. $6^{\text {a }}$ ed. St Louis-Missouri: Mosby-Elsevier; 2006. p 452-72.

11. Silva MEDC, Moura MEB. Representações sociais de profissionais de saúde sobre a hipertensão arterial:contribuiç̧̃̃es para a enfermagem. Esc Anna Nery. 2011; 15(1):75-82.

12. Santos I, Gauthier J, Figueiredo NMA, Petit SH. Prática de pesquisa em ciências humanas e sociais: abordagem sociopoética. São Paulo: Atheneu; 2005.

13. Gauthier J, Hirata M. A enfermeira como educadora. In: Santos I, et al. Enfermagem fundamental: realidade, questões e soluções. São Paulo : Atheneu; 2001.

14. Freire P. Pedagogia do oprimido. Rio de Janeiro: Paz e Terra; 2005.

15. Santos I, Santana RF, Caldas CP. Conversando com idosos: o cuidar/ pesquisar dialógico e sociopoético. Rev Enferm UERJ. 2003; 11(1): 308-16.

16. Dores CNS. PJE: dinâmicas. [citado 2008 set 28]. Disponível em; http://www.cnsfri.com.br/pje12.html..

17. Santos I, Gauthier J, Figueiredo NMA, Tavares CMM, et al. A perspectiva estética no cuidar/educar junto ás pessoas: apropriação da sociopoética. TextodContexto Enferm. 2006; 15( n esp): 31-38.

18. Braz E, Ciosak SI. 0 tornar-se cuidadora na senescência. Esc Anna Nery. 2009; 13 (2): 241-43. 